\title{
Indifferent Gonad
}

National Cancer Institute

\section{Source}

National Cancer Institute. Indifferent Gonad. NCI Thesaurus. Code C34192.

The primordial organ in an embryo before its differentiation into testis or ovary. 